\title{
AVANCES EN ESTUDIOS DE CRECIMIENTO Y FLORACIÓN DE ESPECIES DE Rhodophiala
}

\section{ADVANCES IN STUDIES OF GROWTH AND FLOWERING OF Rhodophalia SPECIES}

\author{
Schiappacasse, F. ${ }^{1}$, Peñailillo, P. ${ }^{1}$, Basoalto, A. ${ }^{1}$, Seemann, P. ${ }^{2}$, Jara, G' ${ }^{2}$ y Muñoz, M. ${ }^{2}$ \\ 'Departamento de Horticultura, Universidad de Talca, Casilla 747, Talca. \\ ${ }^{2}$ Inst. de Prod. y Sanidad Vegetal, Universidad Austral de Chile, Casilla 567, Valdivia. \\ E-mail: fschiap@utalca.cl
}

\section{INTRODUCCIÓN}

El potencial ornamental que muestran diferentes especies de Rhodophiala (geófita nativa) ha estimulado la realización de un proyecto ejecutado entre la Universidad Austral de Chile y la Universidad de Talca, que pretende la creación de individuos poliploides. Con la poliploidía se espera obtener individuos de follaje, varas florales y flores más grandes, los cuales serán más atractivos para diferentes mercados. Durante cuatro años se han buscado protocolos para la inducción de la poliploidía y para la multiplicación in vitro. $\mathrm{Al}$ mismo tiempo, se han realizado estudios tendientes a conocer la morfología y fisiología de la planta, y a lograr un crecimiento rápido de los bulbos.

El objetivo de este trabajo fue la obtención de antecedentes de crecimiento vegetativo y floración a partir de bulbillos de Rhodophiala obtenidos por micropropagación.

\section{MATERIAL Y MÉTODO}

Se utilizaron plantas de 4 especies: Rhodophiala bagnoldii, $R$. montana, $R$. splendens $y \quad R$. rhodolilrion. En el último año se agregó R. aff. laeta. Se observó su crecimiento bajo diferentes condiciones ambientales; se cultivaron bajo invernadero con y sin enfriamiento del aire en el periodo estival; se cultivaron plántulas con y sin calor basal; se cultivaron bajo diferentes condiciones de intensidad lumínica. Se comparó el desarrollo fenológico bajo invernadero y en su ambiente natural. Se realizaron disecciones periódicas de bulbos para conocer su morfología y la evolución de la yema floral. También, por varios años se registró el número de hojas para determinar el período de receso de cada especie y durante el último año se realizaron cruzamientos entre las diferentes especies.

\section{RESULTADOS}

Al registrar el número de hojas de plantas de diferentes calibres durante todo un año, se observó que prácticamente en todos los casos el número fue mayor en las plantas que se encontraban en el invernadero de la estación experimental Panguilemo, el cual está provisto de un sistema de panel húmedo, que enfría el aire y mantuvo una temperatura media de $21^{\circ} \mathrm{C}$ en el mes de enero. El otro invernadero alcanzó temperaturas superiores.

Se sembraron semillas de $R$. bagnoldii, $R$. montana y $R$. splendens y se dispusieron las plántulas a comienzos de julio y hasta noviembre en vasos individuales, en un mesón de propagación con la mitad provista de cables calefactores y la otra mitad sin. Con calor basal la temperatura aproximada promedio fue de $20^{\circ} \mathrm{C}$ y $\sin$ calor basal fue inferior, de aproximadamente $14^{\circ} \mathrm{C}$. Las plantas fueron regadas a partir de agosto con la solución de Cooper, ajustando el $\mathrm{pH}$ según la especie. En $R$. bagnoldii y $R$. montana el diámetro y peso de los bulbos a los cuales se aplicó calor basal fue significativamente superior al de las plantas sin calor basal. En el caso de $R$. splendens sólo el peso del bulbo fue superior en bulbos con calor basal; el diámetro fue igual en ambos tratamientos.

Se realizaron durante dos temporadas diferentes experimentos cultivando plantas de 4 especies bajo distintas condiciones de intensidad de luz, 
no encontrándose diferencias significativas entre los tratamientos.

En el ambiente natural, las especies de cordillera, que son $R$. montana, $R$. splendens y $R$. rhodolirion, muestran un receso estival que comienza después de la floración, la cual ocurre principalmente en enero. El crecimiento se reactiva con las primeras lluvias y el follaje permanece verde incluso bajo la nieve. En $R$. bagnoldii y $R$. aff. laeta, que son plantas del norte, la floración ocurre en primavera. En verano el follaje desaparece, para emerger en mayo o más tarde, según la humedad disponible. Bajo cultivo en invernadero.

Las fechas de floración son similares, excepto para $R$. montana y $R$. bagnoldii, en que se ha observado floración en distintas épocas del año. Para determinar el período de receso se registró durante 4 años el número de hojas en varias plantas (regadas) de $R$. bagnoldii, R. montana $y$ $R$. splendens. Se observó un marcado periodo de receso en $R$. bagnoldii, ya que desde enero a abril desaparece el follaje. En $R$. montana, hay menos hojas entre enero y junio, sin llegar a desaparecer completamente. En $R$. splendens en general hay un menor número de hojas entre enero y marzo.

Al disectar bulbos de las diferentes especies se observó que todas las escamas corresponden a bases de hojas, y todas las especies presentan una morfología similar, en cuanto a que se forman unidades de 3 escamas concéntricas y luego una cuarta escama semienvainadora, que protege a una estructura floral. Estas unidades se repiten dos veces en la temporada, dando origen a dos yemas florales, de las cuales pueden llegar a florecer ambas, una o ninguna. También se observó que los nuevos bulbillos se forman dentro del bulbo madre, entre una escama semienvainadora y los restos de una yema floral. De los cruzamientos efectuados entre las diferentes especies, se obtuvieron semillas viables, que ya están en cultivo.

En resumen, según los estudios, las plantas muestran un mejor comportamiento bajo temperaturas no extremas, y un crecimiento más rápido con calor basal. Por otro lado, el receso parece promoverse con temperaturas altas, aunque hay muchas interrogantes. Los bulbos grandes forman dos yemas florales cada año, y al realizar los cruzamientos se observó una alta compatibilidad entre las especies.

Agro Sur 34 (1-2):29-31 2006

\section{EVALUACIÓN DE 29 CULTIVARES DE PEONÍAS HERBÁCEAS}

(Paeonia lactiflora x P lactiflora, P. lactiflora $x$ P. officinalis,

$P$. lactiflora $x$ P. peregrina, $P$. lactiflora $x$ P. macrophylla $)^{*}$

\section{EVALUATION OF 29 CULTIVARS OF HERBACEOUS \\ PEONIES (Paeonia lactiflora $x$ P. lactiflora, P. lactiflora $x$ P. officinalis, P. lactiflora $x$ P. peregrina, P. lactiflora $x$ P. macrophylla)}

Covacevich, P. y Sáez C.

Universidad de Magallanes, Casilla 113-D, Punta Arenas, Chile, paula_covacevich@yahoo.es

\section{INTRODUCCION}

El cultivo de las flores de corte, es una de las ramas de la horticultura que en las últimas décadas ha cobrado gran importancia en nuestro país como una nueva alternativa de producción rentable, motivo por el cual se ha producido un notable incremento en la superficie dedicada a su explotación, tanto por la introducción de nuevas especies como por la incorporación de nuevas áreas de cultivo.

Dentro de las nuevas especies introducidas está 